\title{
Designing a Green Aircraft Cal Poly's 2009 Undergraduate Aircraft Designs
}

\author{
Robert McDonald ${ }^{1}$ and Bruce Wright ${ }^{2}$ \\ California Polytechnic State University, San Luis Obispo, CA, 93401
}

\begin{abstract}
The Cal Poly senior design class submitted six designs this year in response to the 2009 Undergraduate Team Aircraft Design Competition. This paper summarizes our experiences teaching design through this RFP and brings the student's insights together.
\end{abstract}

\section{Introduction}

$\mathrm{T}$ HE 2008-2009 AIAA Foundation Undergraduate Team Aircraft Design Competition Request for Proposal ${ }^{[1]}$ (RFP) asked for an advanced, environmentally compatible commercial transport design that seats 150 (dual class) passengers with US transcontinental range capability. The design was to show significant improvements in fuel burn (with associated $\mathrm{CO} 2$ reduction) and reduced community noise, while maintaining or improving productivity and passenger comfort standards.

The Senior Aircraft Design course at Cal Poly, San Luis Obispo has evolved over the years into a highly regarded design program ${ }^{[2-9]}$. In the 2008-2009 academic year, the students in the course responded to the design competition with six team submittals. The evolution of the six team designs will be presented from 37 individual student design concepts at the end of fall quarter, creation of team baseline designs at the beginning of winter quarter, four subsequent design iterations and industry critical reviews throughout winter and spring quarters, to submittal of written reports to AIAA in early June 2009.

The cornerstone of the Cal Poly design recipe is close cooperation with industry. The primary components of the cooperation are the trips each Senior Design class makes each year. Each trip has two primary phases. First, an up close tour of a working industry facility. Second, the student participation in a critical review session performed by a panel of technical experts supplied by the company. During 2008-2009, the trips included Boeing Phantom Works in Huntington Beach and Long Beach, Lockheed Martin Skunk Works in Palmdale, Northrop Grumman Integrated Systems in El Segundo, Air Force Test Flight Center at Edwards Air Force Base, and a return visit to Boeing Phantom Works in Huntington Beach with Boeing Commercial Aircraft in Seattle tied in by remote telecommunication.

Each and every critical review session with industry, along with internal pre-reviews with Cal Poly professors and lecturers, resulted in major shifts in team design philosophies and priorities. During the development of individual student design concepts, thinking "outside of the box" was highly encouraged. Representative concepts will be presented with their advanced technology features (Figures $1 \& 2$ ). The major design theme of the six designs chosen for presentation at Boeing Phantom Works was passenger comfort. Most of the designs featured double aisles and larger passenger seats and aisles. Performance improvements over the Boeing 737 and Airbus A320 were small, driven only by improved higher bypass ratio engines. Subsequent discussions regarding the need for improved aerodynamic performance led to most teams adopting high aspect ratio wings, located above the fuselage with strut bracing to reduce wing weight. The historical regression-based weight methodology did not predict matching of (L/D)max and (L/D)cruise. Refined weight models were then created and validated, by comparison with existing transport aircraft, to realistically account for increase of wing weight with increased aspect ratio. Aspect ratio trade studies were then re-evaluated and resulting aspect ratios reduced from 12-27 to 11-12. Most high wing designs with accompanying strut bracing were abandoned with reduction in aspect ratio.

In the end, three teams chose unducted fan engines and three teams chose advanced high bypass ratio turbofans. All unducted fan engines were located on the aft fuselage similar to the MD-80 family of aircraft. Turbofan engines initially were located under the high wing or on the aft fuselage. Engine location trade studies resulted in all three turbofan driven designs adopting over-the-wing locations.

\footnotetext{
${ }^{1}$ Lockheed Martin Assistant Professor, Aerospace Engineering, One Grand Avenue, AIAA Member.

${ }^{2}$ Lecturer, Aerospace Engineering, Program Manager, Lockheed Martin Skunk Works, Retired, AIAA Member.
} 


\section{Individual Student Conceptual Designs}

The students began their individual conceptual designs without a written design priority weighting philosophy. However, a major theme of many of the thirty-seven individual designs was passenger comfort driven by the students experiences as customers rather than the airlines need to minimize fuel burn and to maximize profits.

Wide body designs dominated with dual aisles. Some students went as far as selecting double deck and tandem fuselages. Two factors drove the wide body designs: (1) passenger comfort with each passenger having a window or aisle seat, (2) improved turn-around time of dual aisle loading and unloading.

During the early phase of the design effort, quantitative drag versus weight trade studies of various fuselage configurations were not performed but rather qualitative assessments were made.

The major feedback points from the first industry review at Boeing Phantom Works included:

(1) RFP requirement was for maintaining or improving passenger comfort standards. In the reviewers' opinions, no credit will be given for significant improvement in passenger comfort with resulting increase in drag and fuel burn.

(2) RFP requirement for significant improvement in fuel burn indicates need for improved lift-to-drag ratio, thrust specific fuel consumption, and empty weight. No significant improvement in aerodynamic efficiency was obtained by majority of designs with the wider fuselages exhibiting increased frontal areas and resulting increased fuselage drag.

The wing aspect ratios varied from 4.9 to 12 with an overall average of approximately 9.7, comparable to the Boeing B737 and Airbus A320. Wing sweep and thickness were also similar to that of the B737 and A320.

It was recommended that the follow-on designs improve aerodynamic efficiency by adopting narrow body single aisle fuselages to minimize $\mathrm{CD}_{\mathrm{o}}$ and increase wing aspect ratio to improve induced drag. The reviewers indicated their internal figure of merit is to maximize span squared divided by wing wetted area.

After the Boeing trip and upon completion of student feedback discussions, six teams were formed represented by five or six students. Each team was to continue the conceptual design process.

After the first week of attempting to establish team baseline designs to serve as a basis for concept trade studies, little progress was being made. Since the next industry briefing was scheduled for mid February, it was essential that the trade studies begin in earnest. The first week was overshadowed by internal team haggling with each student defending his or her individual design as a basis for the team baseline. In an effort to move the teams along, one of the advisors stated: "I would start the design process with single aisle, aft-fuselage mounted unducted fan propulsion, high aspect ratio wing with hybrid laminar flow control system." This was a big mistake because overnight all six teams abandoned their "out of the box" designs and adopted more conventional designs, never returning to more aggressive design philosophies. 


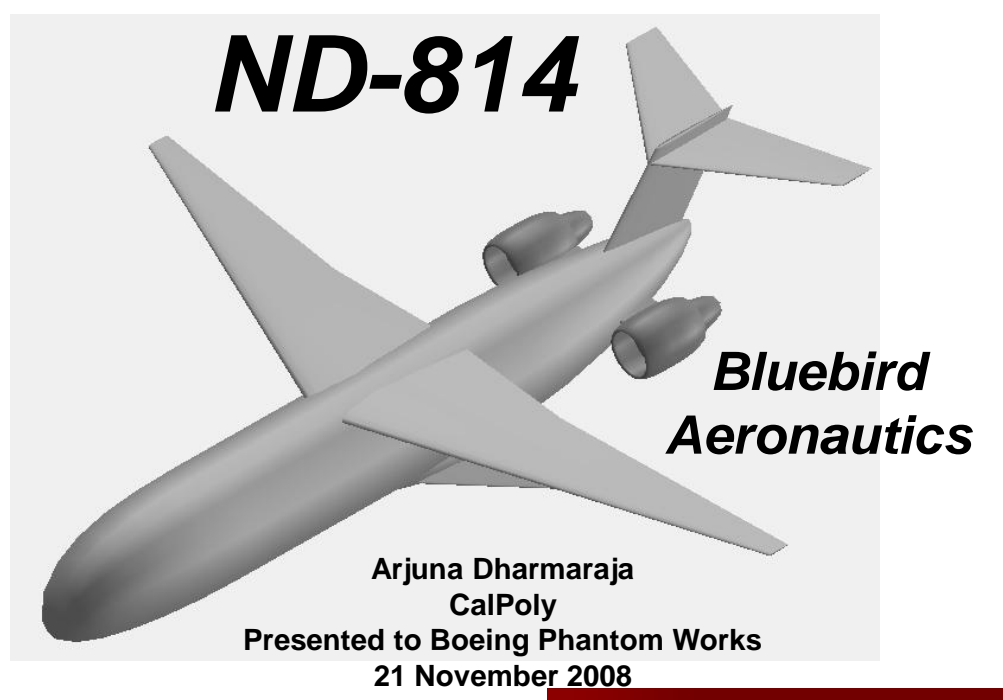

\section{Green Aerospace VX-Twin}

An Advanced, Environmentally Compatible,

150-seat Commercial Transport

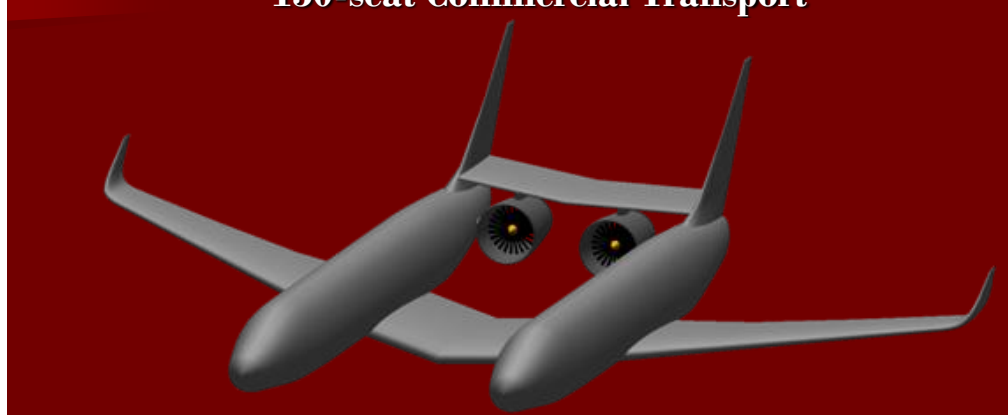

Presented to Boeing Phantom Works

Michael Green

California Polytechnic State University, SLO

November 21, 2008

Gnat Aviation PRESENTS THE GA 237

Natalie R. Smith

California Polytechnic State University Presented to Boeing Phantom Works

November 21, 2008

Figure 1. Representative individual study concepts. 


\section{The Jolly Green Giant}

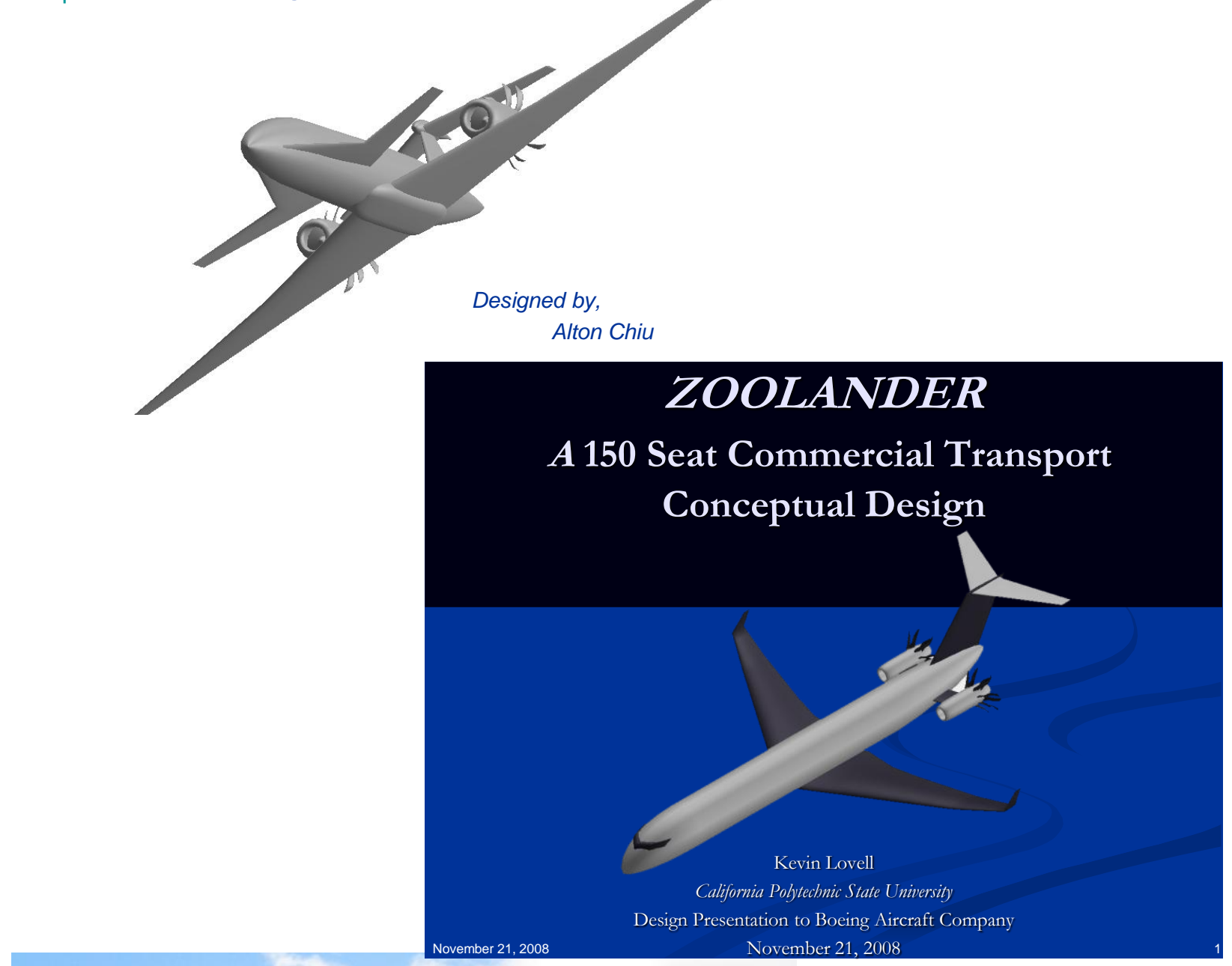

\section{The Albatross}

Prepared For:

Boeling Phantom Works

November 21, 2008
Designned loy:

Fletcher Hartshorm

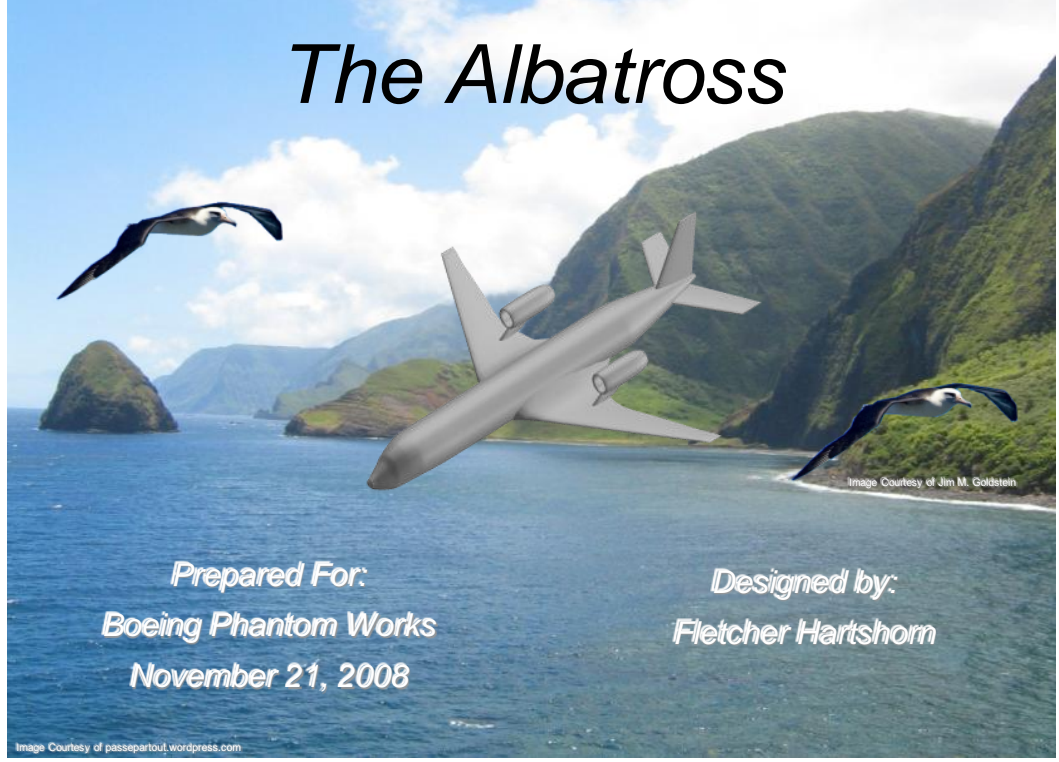

Figure 2. More individual study concepts. 


\section{The Evolution of One Team Design}

One of the six team designs was selected to trace the evolutionary process through the first design iterations and subsequent design reviews from early January through early June 1999. That design was named DT-6 Luigi by the student design team.

\section{A. Iteration 1}

Iteration one was presented to the Lockheed Martin Skunk Works on February 20, 2009. First the design team established a weighting scheme for determining team priorities for the conceptual design process. The weighting scheme is outlined in Table 1. The largest design driver was to decrease fuel burn. Reducing fuel burn in turn reduces aircraft weight, cost, and emissions. Another large design driver was community noise. The RFP calls for a $-20 \mathrm{~dB}$ reduction in noise from CAEP 4 limits. The resulting design is shown in Figure 3.

Table 1. Main weighting scheme which drove the design of Luigi.

\begin{tabular}{|c|c|}
\hline Community Impact & Overall Weight \\
\hline Reduce exterior noise & 0.18 \\
\hline Reduce emissions ( $\left.\mathrm{CO}_{2}\right)$ & 0.05 \\
\hline \multicolumn{2}{|l|}{ Productivity / DOC } \\
\hline Increase in-air performance & 0.02 \\
\hline Decrease turnover time & 0.04 \\
\hline Decrease maintenance / servicing & 0.04 \\
\hline Improve cabin / cargo layout efficiency & 0.02 \\
\hline Decrease fuel burn & 0.60 \\
\hline \multicolumn{2}{|l|}{ Passenger Comfort } \\
\hline Reduce interior noise & 0.01 \\
\hline Optimize interior layout & 0.04 \\
\hline
\end{tabular}

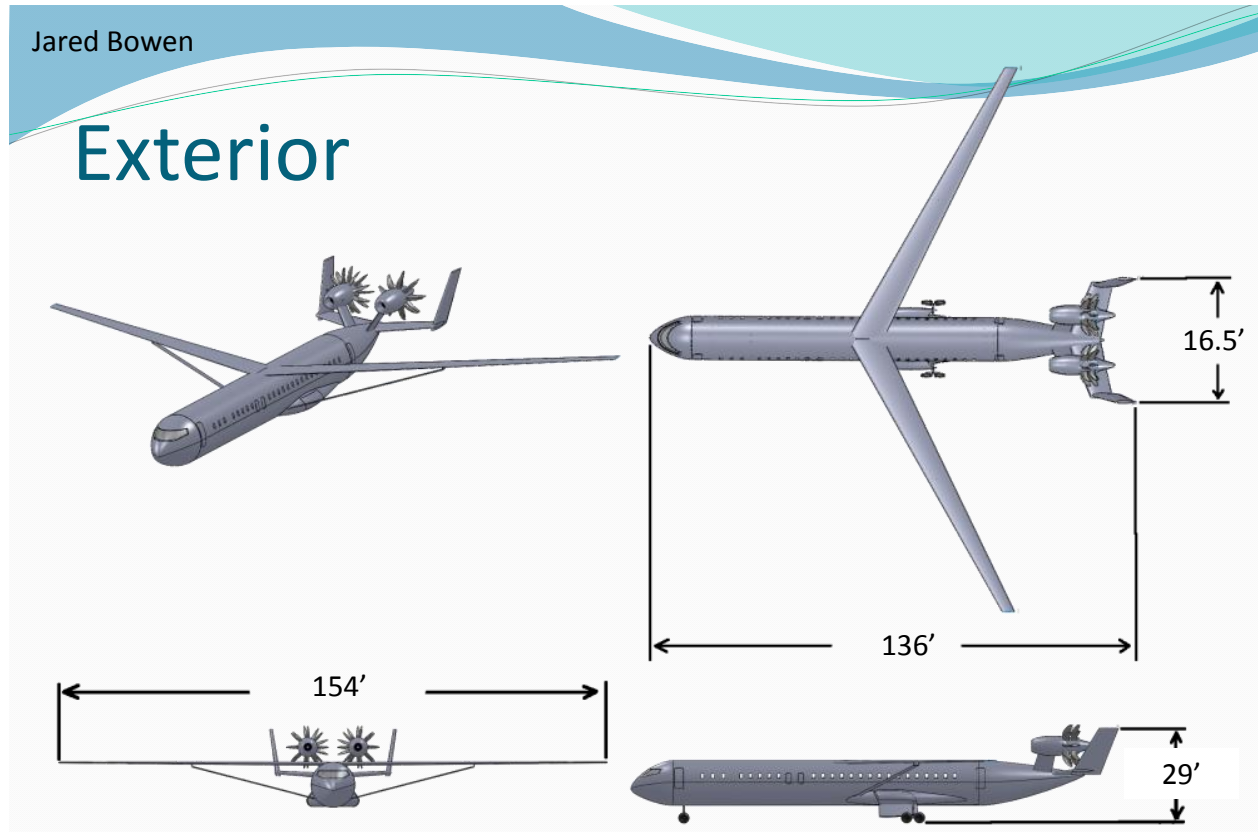

Figure 3. First iteration of DT-6 Luigi.

5

American Institute of Aeronautics and Astronautics 
This concept shows the traceability back to the suggested starting point concept with the following features:

- Narrow body, single aisle, staggered six abreast seating, cigar shaped fuselage.

- Aft-fuselage, top mounted unducted fan engines with U-tail noise shielding.

- Strut-braced, high wing with a 150 foot span, aspect ratio of 22.5 and leading edge sweep of 29 degrees.

- NASA SC-2 series supercritical airfoil design

The (L/D)max at 35,000 feet cruise altitude was calculated to be 26.5 at a lift coefficient of 0.95 . The aircraft wants to cruise at a lift coefficient of 0.55 , far below that for maximum aerodynamic efficiency, resulting in a bad match due to the extremely high wing aspect ratio. Allowing the aircraft to cruise at 41,000 feet altitude as fuel is burned better matches the cruise lift coefficient to maximize aerodynamic efficiency.

The very high aspect ratio wing required strut bracing to reduce wing weight. Even so, it became obvious that the regression based weight methodology of Nicolai ${ }^{[12]}$, Raymer ${ }^{[10]}$ and Roskam ${ }^{[11]}$ did not predict the true weight penalties of high aspect ratio wings.

\section{B. Iteration 2}

The second iteration was presented at Northrop Grumman on March 13, 2009. During the formulation of iteration two a quasi analytical wing weight methodology was developed to replace the regression based weight methodology. Other issues were considered including the flutter characteristics of the strut. Also, the high wing causes the center of gravity of the aircraft to become higher off the ground. This presented a problem with turn-over angle in which the closely spaced landing gear would have to fold outward from the fuselage. The high wing also resulted in the added complexity of landing gear pods attached to the fuselage. This added an extra load path from the bottom of the fuselage to the top where the wing was placed, which in turn adds weight.

Another problem with the high aspect ratio wing was the issue of airport compatibility. The RFP called for an aircraft to replace the B737 class of aircraft. With Luigi's 150 feet wing span, the aircraft was outside of Class III aircraft span limits of less than 118 feet span. Depending on how the RFP was interpreted, this would be at best an inconvenience to the airlines, and at worst, a violation of the RFP requirements.

A new wing aspect ratio trade study was performed utilizing the quasi analytical wing weight methodology. The trade study compared fuel burn per seat for various aspect ratios between five and twenty-five for a typical 500 nautical mile mission while allowing cruise altitude to vary from 35,000 to 43,000 feet. Minimum fuel burn was obtained at an aspect ratio of 12.6. The resulting design, Iteration two, is shown in Figure 4. Iteration 1 and 2 are compared in Table 2 .
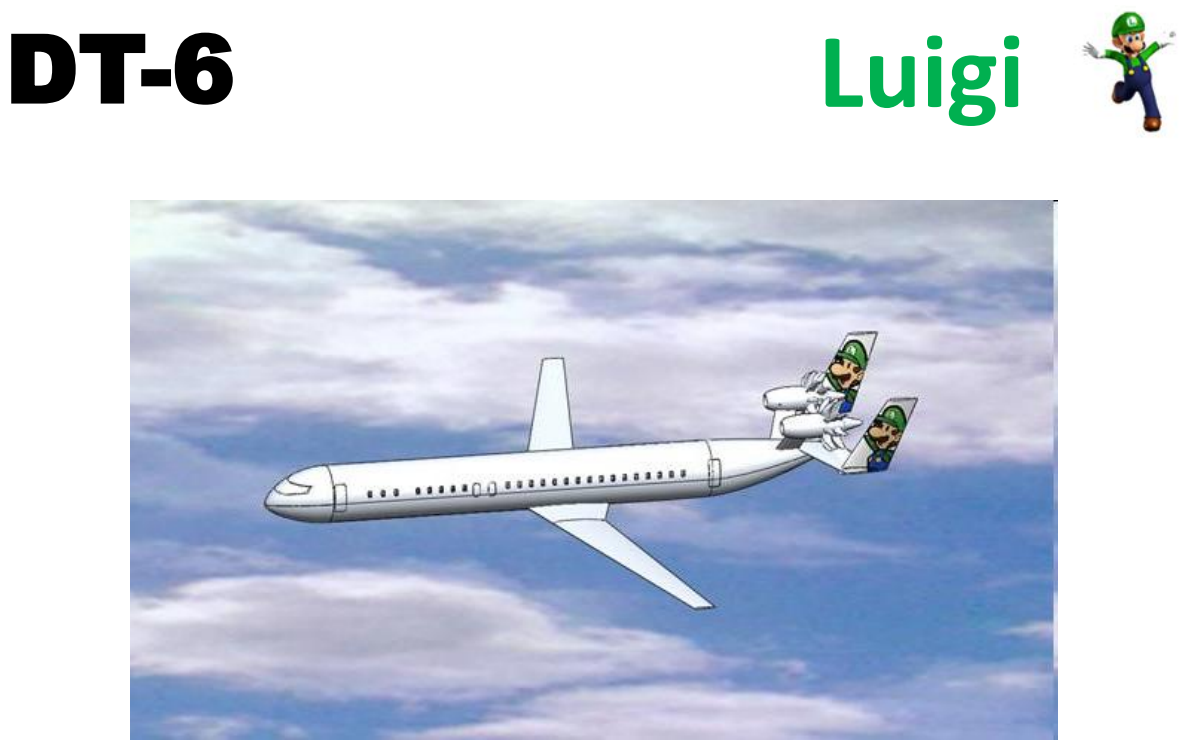

\section{Presented to Northrop Grumman}

Friday March 13, 2009

Figure 4. Iteration two of DT-6 Luigi. 
Table 2. Luigi iterations 1 and 2 comparison.

\begin{tabular}{|l|l|l|}
\cline { 2 - 3 } \multicolumn{1}{c|}{} & \multicolumn{1}{c|}{ Iteration 1 } & \multicolumn{1}{c|}{ Iteration 2 } \\
\hline Fuselage & Single aisle & Same \\
\hline Propulsion & $\begin{array}{l}\text { Aft-fuselage mounted } \\
\text { unducted fan engines } \\
\text { with }\end{array}$ & Same \\
\hline Wing & $\begin{array}{l}\text { Strut-braced high wing } \\
\text { AR }=26.5 \\
\text { Span =150ft }\end{array}$ & $\begin{array}{l}\text { Conventional low wing } \\
\text { AR = 12.6 } \\
\text { Span = 130ft }\end{array}$ \\
\hline Tail & U-Tail Noise shielding & Same \\
\hline
\end{tabular}

\section{Iteration 3}

Iteration three was presented at the return visit to Boeing Phantom Works on April 24, 2009 and to the USAF Flight Test Center on April 30, 2009; iteration three is presented in Figure 5. Continued refinement of weight estimation methodology led to performing a component weight breakdown study and comparison. Three models, comprised of historical regression equations were used. The first model taken into consideration was from Raymer which was designed for cargo/transport aircraft and broke the aircraft down into nineteen separate component groups. The second model was from Roskam, which broke the aircraft into sixteen different component groups. The third model was from Nicolai. All three models used the actual Boeing 737-800 weights for validation. The three models under predicted the empty weight by $27 \%, 10 \%$, and $32 \%$, respectively. Also, none of the models were sensitive to configuration changes.

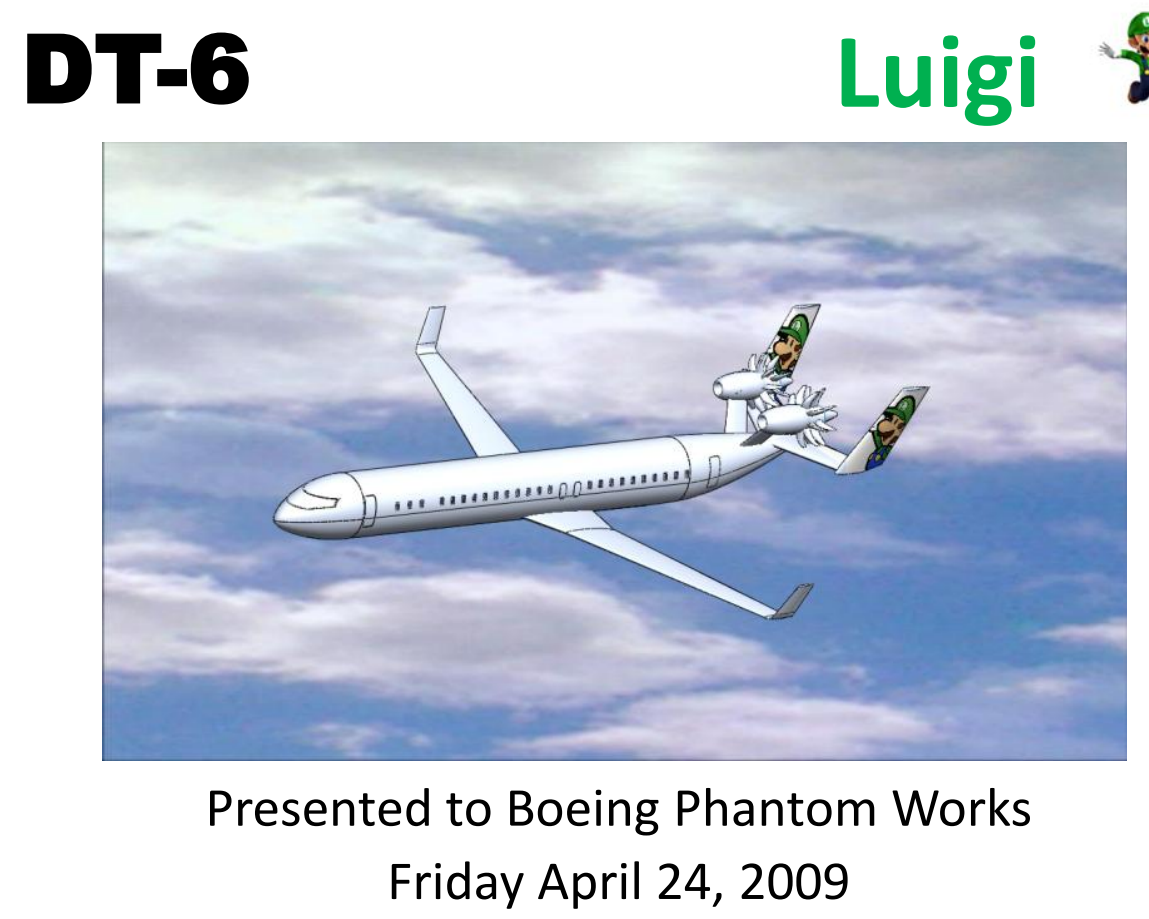

Figure 5. Iteration three of DT-6 Luigi.

Finally a weight estimation model was created that was sensitive to changes in wing aspect ratio. This was achieved by adapting the wing weight model from NASA's wing weight build-up weight methodology with modification for material and construction techniques. This model finds an optimal weight for the wing structural components based on the actual loads encountered during flight. Historical regression is then used to determine a total wing weight based on the optimal weight. This model also breaks the wing down into various components such as fixed leading edges, high lift devices, and spoiler/speed brakes. This is useful in applying weight savings due to composites to only certain components of the wing which actually use composites. When applying the new 
wing weight model to the aspect ratio trade study, it was found that the wing aspect ratio found for minimum fuel burn was acceptable. However, the weight model did not accurately model the weight increases due to the aeroelastic effects at high aspect ratios.

While iterating through the weights code with changes in wing weight, care was taken to make sure that the weight of components, such a furnishings and air conditioning systems would not change with the increase in weight. Thus for the newly created hybrid model, the weights of various components were scaled from data on similar aircraft and held constant throughout the iterative process. The remaining component weights were still determined using historical regression equations from Raymer and Roskam. Empty weight estimation was validated using the Boeing 737-800. It was found that the hybrid weights model estimated the 737-800 within 3\%. The hybrid model was then further validated for other components using the 737-200, for which data existed. The fuselage weight varied $5 \%$, wing $2 \%$, empennage $3 \%$, and landing gear $1 \%$.

Table 3 shows the comparisons of the first three iterations.

Table 3. Comparison of Luigi iterations 1-3.

\begin{tabular}{|l|l|l|l|}
\cline { 2 - 4 } \multicolumn{1}{c|}{} & \multicolumn{1}{c|}{ Iteration 1 } & \multicolumn{1}{c|}{ Iteration 2 } & Iteration 3 \\
\hline Fuselage & Single aisle & Same & Same \\
\hline Propulsion & $\begin{array}{l}\text { Aft-fuselage mounted } \\
\text { unducted fan engines } \\
\text { with }\end{array}$ & Same & Same \\
\hline Wing & $\begin{array}{l}\text { Strut-braced high wing } \\
\text { AR }=26.5 \\
\text { Span }=150 \mathrm{ft}\end{array}$ & $\begin{array}{l}\text { Conventional low wing } \\
\text { AR }=12.6 \\
\text { Span }=130 \mathrm{ft}\end{array}$ & $\begin{array}{l}\text { Conventional low wing } \\
\text { AR }=12.6 \\
\text { Span }=117 \mathrm{ft} \\
\text { Winglets }\end{array}$ \\
\hline Tail & U-tail Noise shielding & Same & Same \\
\hline
\end{tabular}

\section{Iteration 4}

Iteration four concept was presented at the in-house yearly Aerospace Engineering Symposium on May 15, 2009 and is shown in Figure 6.

\section{DT-6}

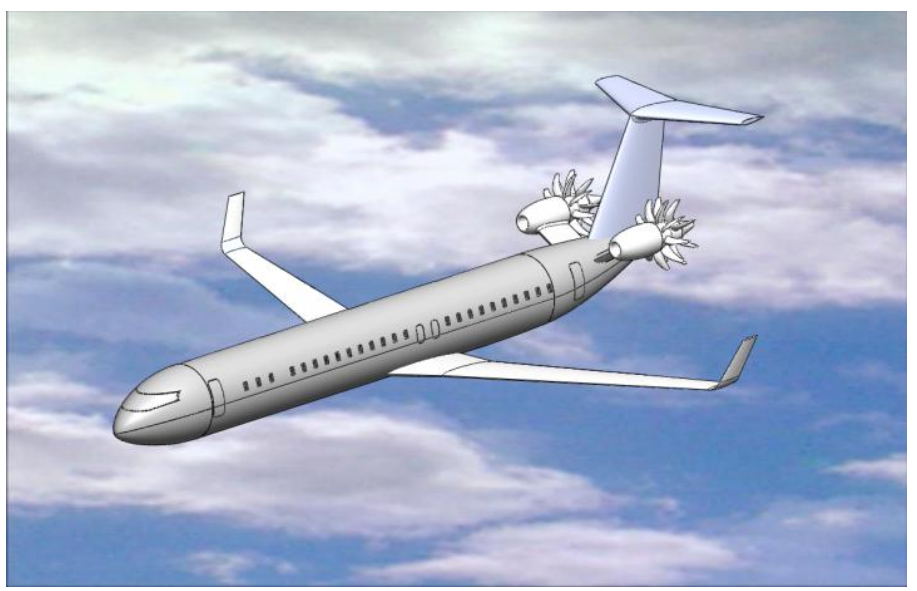

Presented to the Cal Poly

Aerospace Engineering Symposium

Friday May 15, 2009

Figure 6. Iteration four of DT-6 Luigi. 
The DT-6 design team used the AIAA design competition as a learning experience to help improve the team's understanding of the conceptual design process and the methods involved. To help further this goal, most of the tools used to design the aircraft were developed by the team. If the team was to have used an aircraft multidiscipline design code such as FLOPS ${ }^{[13]}$, there would have been a lack of knowledge on what exactly goes into the design process and how each piece functions. Therefore, the team believed that developing its own tools was the most educational and helpful for future projects. Since the team developed most of the tools used in designing the aircraft, it was necessary to make sure the numbers calculated for the aircraft were reasonable. To do this, the team validated the tools that were developed against current aircraft with known data.

We have already discussed in detail the development and validation of the hybrid weight estimation methodology. In addition, drag polar estimation methods were developed and validated using the McDonnell Douglas DC-10-40 because drag polar data was readily available from manuals. The derived drag buildup method was on average only $2.1 \%$ different from the actual DC-10-40 data. The derived mission analysis code was also validated using the DC-10-40 data. Evaluating three missions, the average differences in fuel burn was $1.3 \%$.

Community noise calculations using NASA's ANOPP ${ }^{[14]}$ code indicated that noise levels below the ICAO chapter 4 minus $20 \mathrm{~dB}$ requirement could be met without U-tail shielding. Thus in Iteration 4 , the U-tail was replaced by a T-tail arrangement to maximize the tail moment arm and minimize tail area.

Further, the wing aspect ratio was refined through further trades from 12.6 to 13 . The final conceptual design, submitted to the AIAA in June 2009, is shown in Figure 7 and Table 4 compares all four iterations.

Table 4. Comparison of Luigi iterations 1-4.

\begin{tabular}{|l|l|l|l|l|}
\cline { 2 - 5 } \multicolumn{1}{c|}{} & \multicolumn{1}{c|}{ Iteration 1 } & \multicolumn{1}{c|}{ Iteration 2 } & \multicolumn{1}{c|}{ Iteration 3 } & \multicolumn{1}{c|}{ Iteration 4 } \\
\hline Fuselage & Single aisle & Same & Same & Same \\
\hline Propulsion & $\begin{array}{l}\text { Aft-fuselage mounted } \\
\text { unducted fan engines }\end{array}$ & Same & Same & Same \\
\hline \multirow{2}{*}{ Wing } & Strut-braced high wing & Conventional low wing & Conventional low wing & Same \\
& AR $=26.5$ & AR $=12.6$ & AR $=12.6$ & AR $=13$ \\
& Span $=150 \mathrm{ft}$ & Span $=130 \mathrm{ft}$ & Span $=117 \mathrm{ft}$ & Same \\
& & & Winglets & Same \\
\hline Tail & U-tail Noise shielding & Same & Same & T-tail \\
\hline
\end{tabular}

\section{Similar Design Processes for Other Five Teams}

The other five design teams followed similar paths to reach their final conceptual designs. 3-view drawings of the other final designs are shown in Figures 8 through 12.

\section{Conclusions}

The 2008-2009 Cal Poly Senior Aircraft Design was an unqualified success. Six student teams entered the AIAA Team Aircraft Design Competition; Hummingbird Aeronautics was awarded second place for their design the Tersus. All those involved, students and instructors alike, learned a lot about aircraft design. This paper has attempted to tell some of the story of the evolution of the student designs and of their knowledge of design.

For those who are interested, all six team's final design reports are available online for download at http://www.flightlab.calpoly.edu/html/design_reports/.

\section{Acknowledgments}

The aircraft design program at Cal Poly would not be possible without the tremendous support given to us by the Aerospace Industry, their employees, and our alumni. In the 2008-2009 academic year, the aircraft design class was hosted by Boeing Commercial Aircraft and Phantom Works in Long Beach and Huntington Beach, Lockheed Martin Skunk Works in Palmdale, Northrop Grumman in El Segundo, and the Air Force Flight Test Center at Edwards Air Force Base. Thanks also to everyone who attended the annual Symposium in San Luis Obispo. Finally, thanks to all the students past and present who make Cal Poly what it is. 


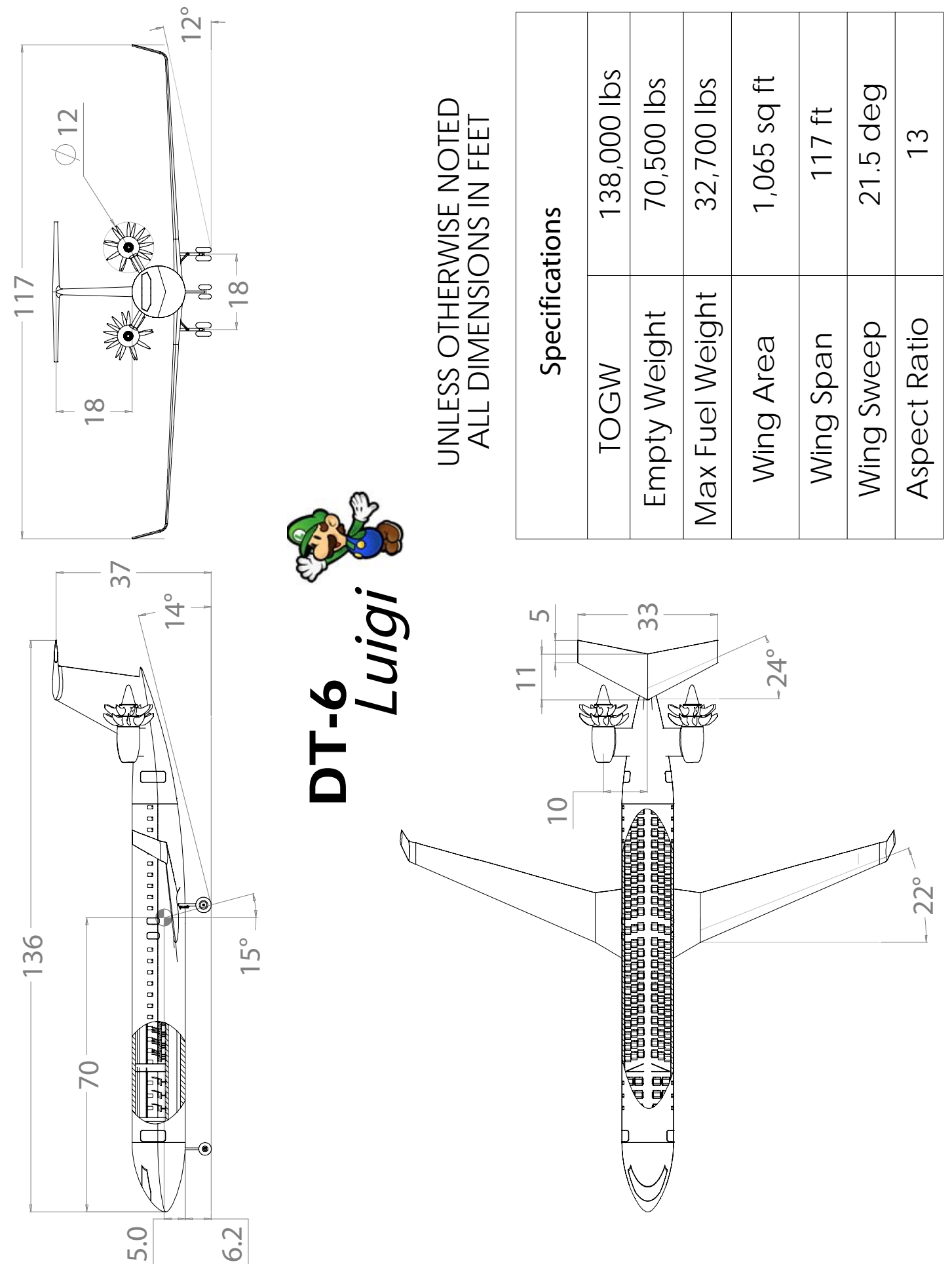

Figure 7. Final design of DT-6 Luigi. 


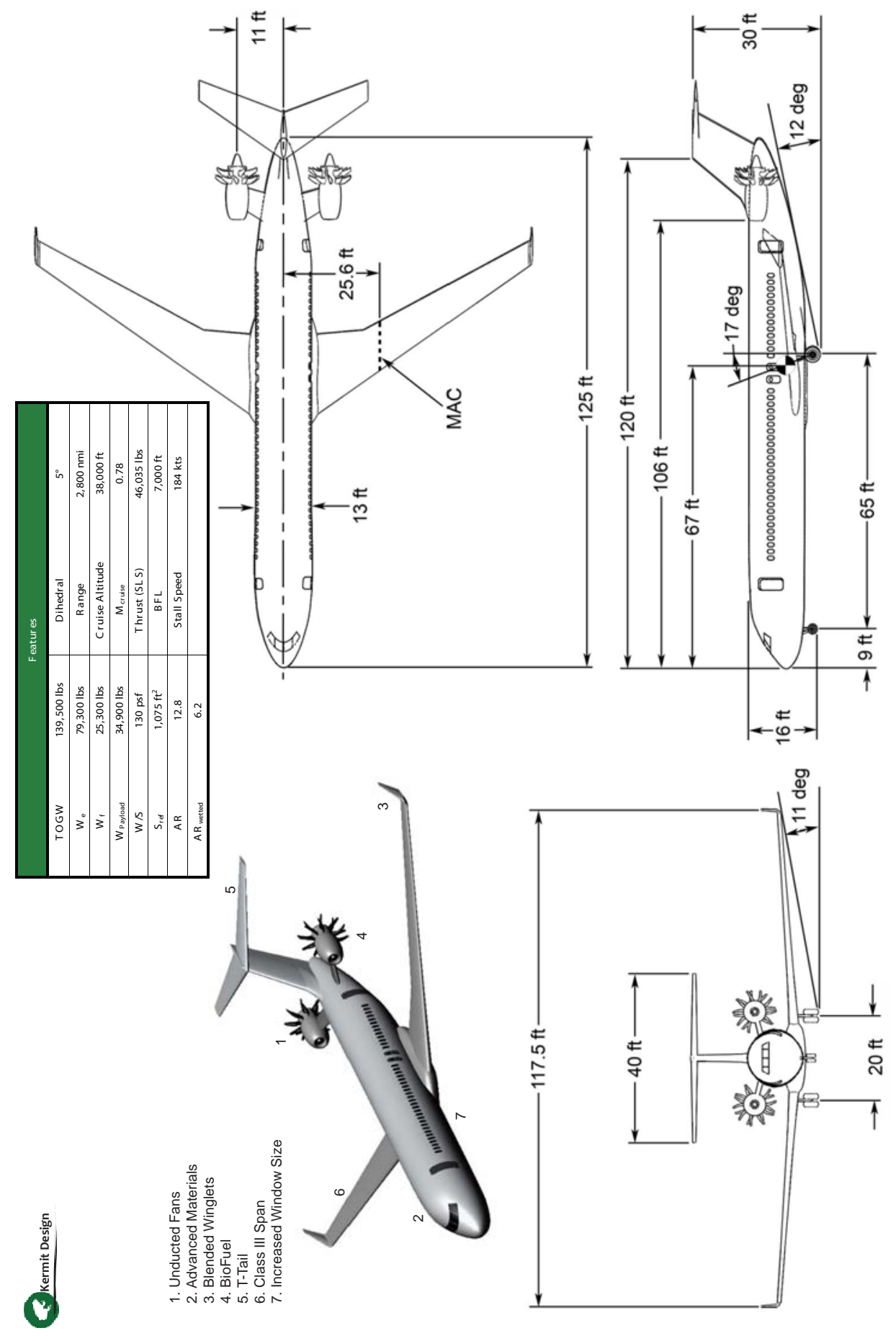

Figure 8. Final design of Kermit Design Verde. 


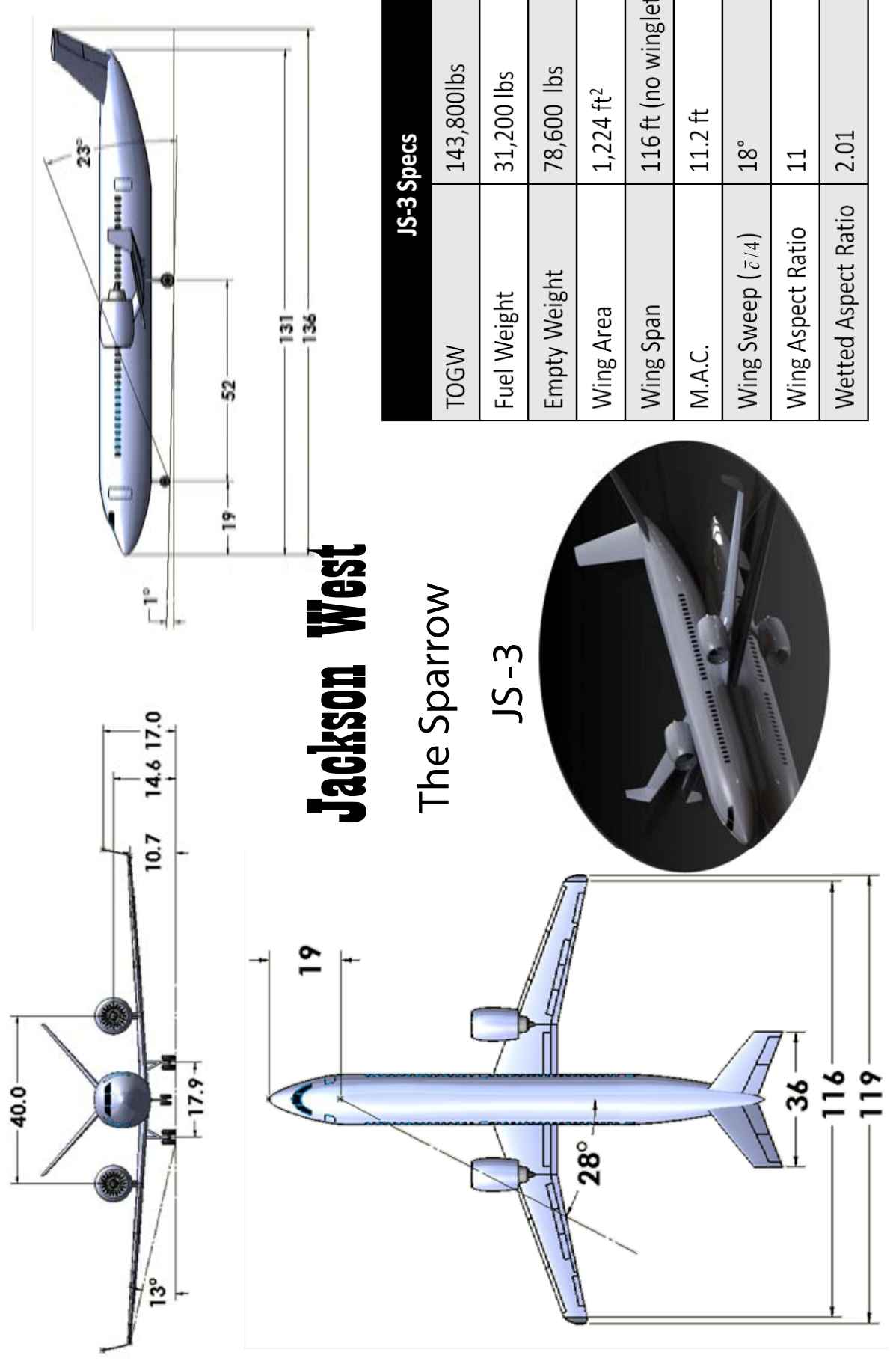

Figure 9. Final design of Jackson West Sparrow. 


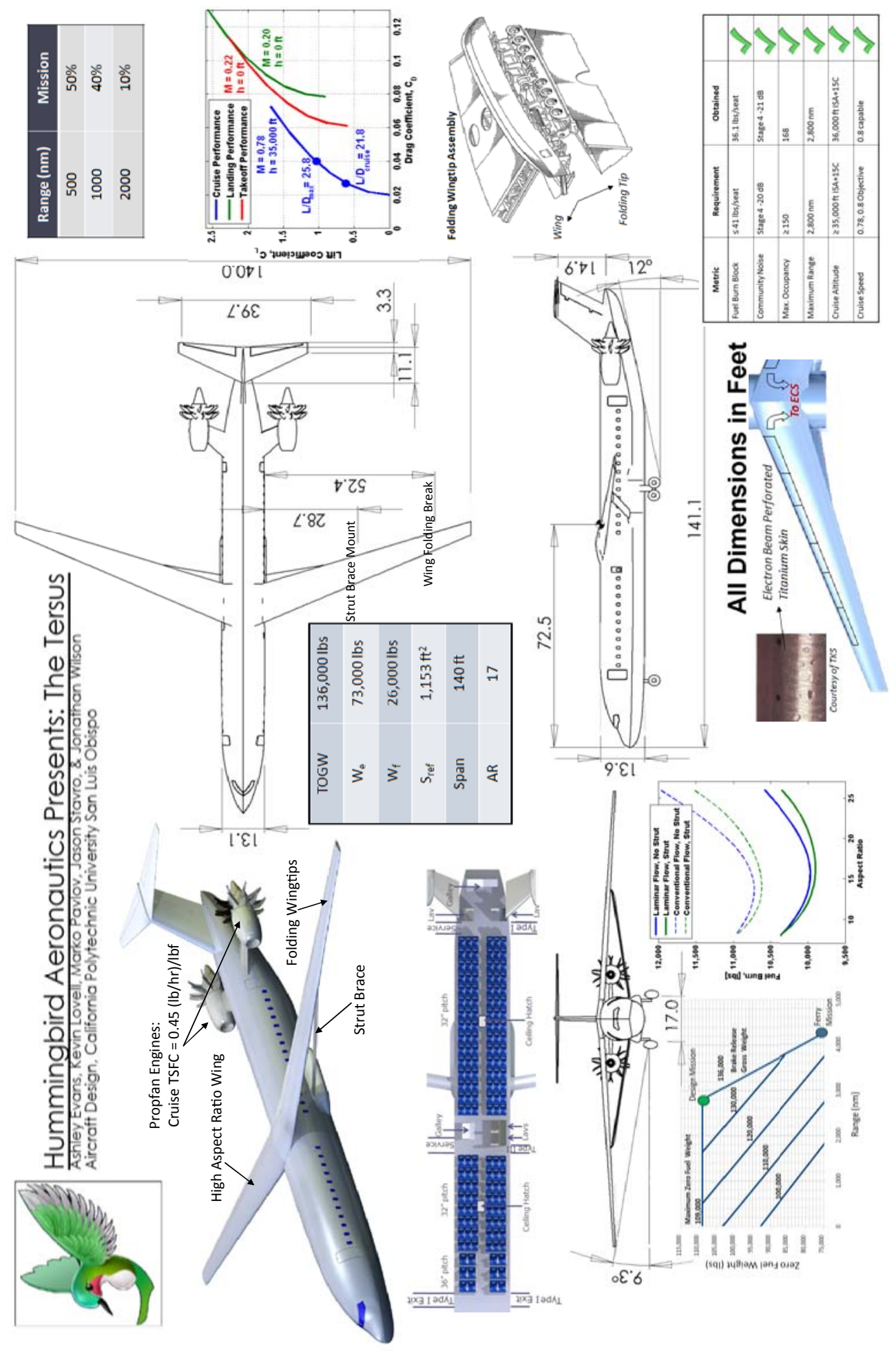

Figure 10. Final design of Hummingbird Aeronautics Tersus. 

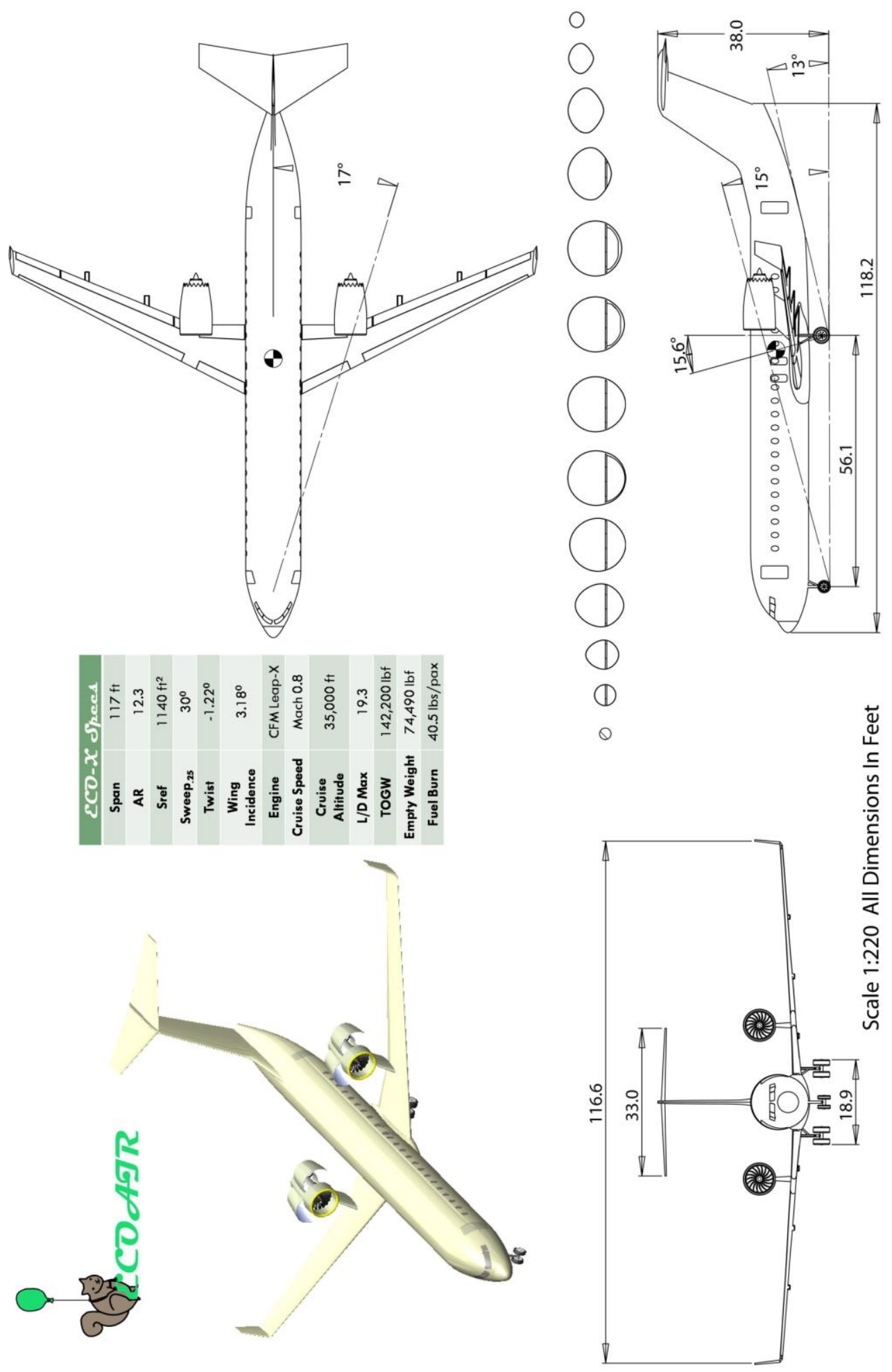

Figure 11. Final design of Ecoair ECO-X. 

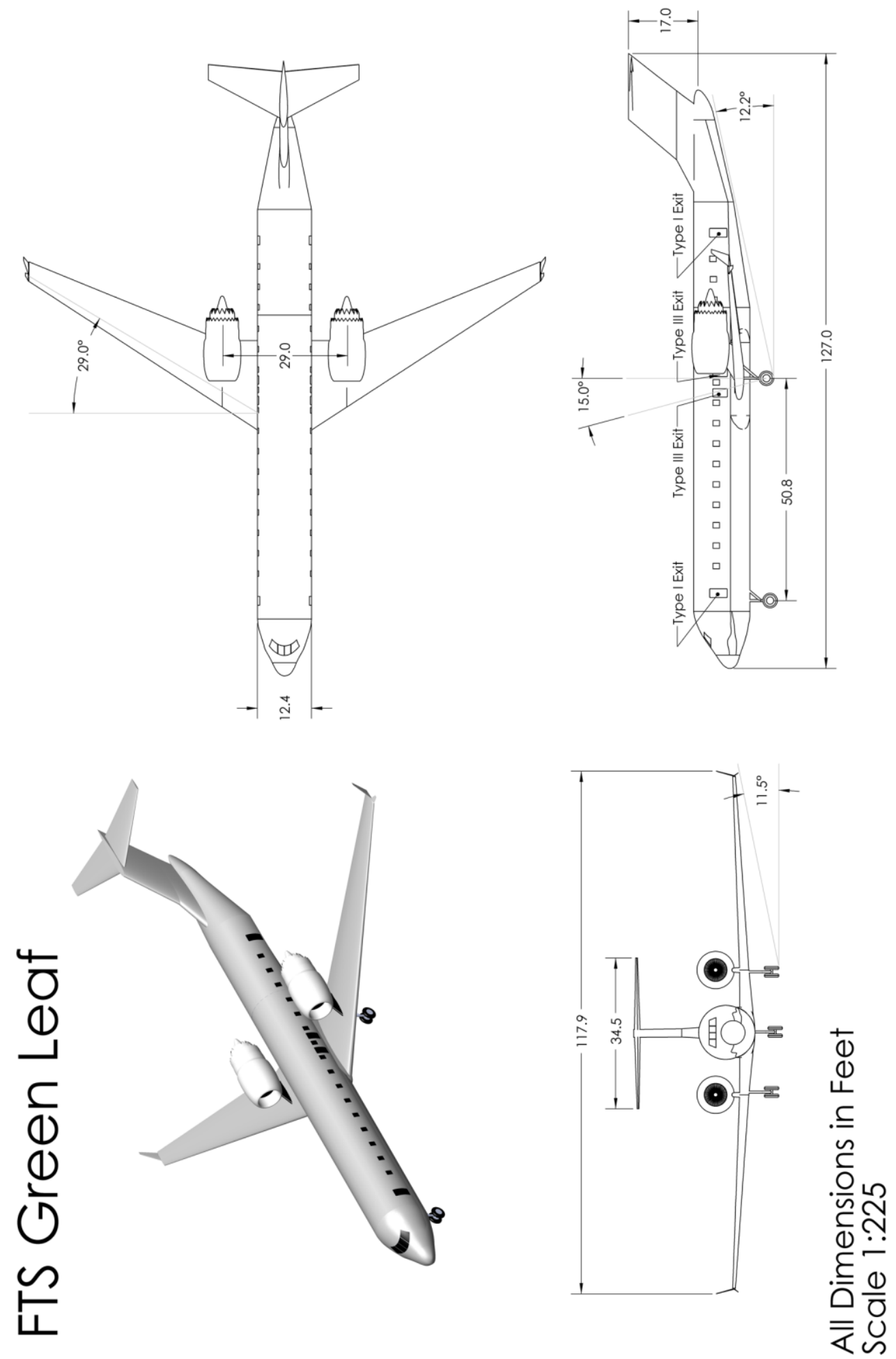

Figure 12. Final design of FTS Green Leaf. 


\section{References}

${ }^{1}$ Anon., "Advanced, Environmentally Compatible, 150 Seat Commercial Transport", Request for Proposal 2008-2009 Undergraduate Aircraft Design Competition, American Institute of Aeronautics and Astronautics, Inc., Reston, Virginia, 2008.

${ }^{2}$ McDonald, R., Puig-Suari, J., Esposto, D., and Wright, W., "Senior Design at Cal Poly: A Recipe for Success," $47^{\text {th }}$ AIAA Aerospace Sciences Meeting, Orlando FL, AIAA Paper 2009-1623, Jan. 2009.

${ }^{3}$ Cummings, R.M., Hall, D.W., and Sandlin, D.R., "Decades of Innovation in Aircraft Design Education," 47 $7^{\text {th }}$ AIAA Aerospace Sciences Meeting, Orlando FL, AIAA Paper 2009-1603, Jan. 2009.

${ }^{4}$ Hall, D.W., and Cummings, R.M., "The Happy Accidents of Teaching Aircraft Design," AIAA 45th Aerospace Sciences Meeting, Reno NV, AIAA Paper 2007-0302, Jan. 2007.

${ }^{5}$ Cummings, R.M. and Hall, D., "Aircraft Design for Second-Year Undergraduate Students," International Journal of Engineering Education, Vol. 21, No. 2, 2005, pp. 341-349.

${ }^{6}$ Cummings, D.B. and Hall, D.W., "Exploiting the Creative Process for Innovative Air Vehicle Design," AIAA 42 ${ }^{\text {nd }}$ Aerospace Sciences Meeting, Reno NV, AIAA Paper 2004-0417, Jan. 2004.

${ }^{7}$ Cummings, R.M., "From Biplanes to Reusable Launch Vehicles: 75 Years of Aircraft Design at Cal Poly," AIAA 41 Aerospace Sciences Meeting, Reno NV, AIAA Paper 2003-0233, Jan. 2003.

${ }^{8}$ Soban, D.S., "Aircraft Design Education-A Student's Perspective," AIAA Aircraft Design, Systems, and Operations Meeting, Monterey CA, AIAA Paper 93-3993, Aug. 1993.

9Sandlin, D.R. and van't Riet, R., "The Cal Poly Aircraft Design Program,” AIAA Aerospace Design Conference, Irvine CA, AIAA Paper 93-1111, Feb. 1993.

${ }^{10}$ Raymer, Daniel P. Aircraft Design: A Conceptual Approach. Reston: American Institute of Aeronautics and Astronautics, Inc., 1999.

${ }^{11}$ Roskam, Jan. Airplane Design Part I-VII, Roskam Aviation and Engineering Corporation, 1989.

${ }^{12}$ Nicolai, Leland M., Fundamentals of Aircraft Design, Mets Inc., Dayton, OH, 1975.

${ }^{13}$ McCullers, LA, "FLOPS: Flight Optimization System", ATK Space Division, 2008.

${ }^{14}$ ANOPP. Aircraft Noise Prediction Program. NASA. 1982 